\title{
THE SILENT HISTORY OF VERNACULAR: EMERGENT PROPERTIES AS BACKGROUND FOR STUDYING TECHNOLOGICAL EVOLUTION IN THE BUILT ENVIRONMENT
}

\author{
HELEN WILKINS \\ Department of Archaeology (PHA) \\ University of Sydney \\ 13 Burchmore Rd, Manly Vale NSW 2093, Australia \\ hmwilkins@optusnet.com.au
}

\begin{abstract}
All complex systems, which includes buildings and the built environment, possess emergent properties. Complex systems are systems that are composed of numerous interacting parts. Emergent properties are high-level behaviours that arise spontaneously as a result of the structural organisation of, and the interactions between, the individual parts and properties of the system. Thermal performance is an emergent property of buildings and of the built environment. It is the result of the way in which the physical components of a built environment and their thermal properties interact.

Understanding the emergent thermal properties of the built environment is important because there has been an empirically verifiable long term trend in the way classes of buildings have altered over time. Vernacular buildings that have persisted for long spans of time possessed technologies that 'managed' the emergent thermal properties, and their inherent thermal contradictions, whether their builders or occupants have been aware of this or not: they are silent technologies. Classes of buildings that did not possess these silent technologies have, over time, fallen out of use and have not reappeared. As buildings have become ever more complex, these silent technologies have become ever more sophisticated overall in their 'management' of the emergent thermal properties. This has allowed the overall level of thermal choices and control available to building occupants to increase over time, regardless of their contradictory natures.
\end{abstract}

Keywords: Emergent properties, complex systems, vernacular, thermal choices; thermal control.

\section{Introduction}

The application of technologies in buildings and the built environment has not always been overt and obvious. Buildings and the built environment, as complex systems, possess emergent properties and technologies that 'manage' emergent properties have existed in vernacular buildings dating back to the time of the earliest built structures, whether their participants were aware of their presence or not. Understanding these silent technologies is important because complex systems have often shown long term trends in the way they have changed over time (cf. climate, the economy), regardless of whether the participants are aware of the presence of these trends or not. For example, animals need not be aware of the processes operating within biological evolution for it to be an empirically demonstrable phenomenon. 
Thermal performance is an emergent property of buildings and of the built environment. Understanding thermal emergent properties is important because there has been an empirically verifiable long term trend in the way classes of buildings have altered over time. The people involved need not have been aware of the presence of this underlying trend for it to be empirically verifiable. The very essence of vernacular is quantifiable change within ordinary, non-monumental and non-architecturally-designed buildings that occurs over spans of time that potentially exceed the awareness of the people involved.

This paper outlines an analysis of the emergent thermal properties of a wide sample of vernacular buildings over an extended period of time. It demonstrates that, as buildings became more complex (with more rooms, more levels, more variation in room size and shape) the technologies for 'managing' emergent thermal properties became ever more sophisticated (incorporating more closeable-openings, more transitional spaces, more courtyards, more environmentally-altering devices such as windcatchers, evaporative coolers, braziers). More importantly, however, the most successful and longest surviving forms of vernacular buildings have been those in which the silent technologies were able to enhance the thermal choices and control available to the building occupants, regardless of the contradictory nature of thermal choices and control.

\section{Emergent Properties}

Emergent properties arise spontaneously within complex systems, systems that are composed of numerous interacting parts, such as the environment, the economy, the internet, buildings and the built environment. They are high-level behaviours that arise spontaneously as a result of the structural organisation of, and the interactions between, the individual parts and properties of the system. The ability of a car to move is an emergent property of cars and the mind is an emergent property of the brain (Cohen \& Stewart 2000: 169). A car's capacity to move and a brain to think cannot be studied directly in terms of the individual components, or extrapolated from them. The 'drivability' of a car and the mental capacity of a brain have, however, been studied extensively and intensively, not so much as the raison d'etre of cars and brains, but as a consequence of their structure and workings (Eldredge 1989; Conway Morris 1998: 9).

Emergent properties are empirically measurable when observed at the scale of the whole system and, whilst they cannot be extrapolated from a quantitative analysis of only individual parts, some features will have a greater influence on the nature of the emergent properties than others. Additionally, the nature of emergent properties is often the result of contradictions that are inherent within complex systems (Kauffman 1995). These include contradictory processes operating within the system and the way in which the contradictions are resolved (Gould \& Lewontin 1984; Kauffman 1995: 171-178). For example, an aeroplane's capacity to fly is an emergent property that arises from the finding of an appropriate compromise between the contradictory requirements of structural strength, flexibility and weight. Finding better and better compromises, however, becomes exponentially more difficult as better compromises are found (Kauffman 1995: 203-205).

\section{Buildings as Thermal Machines}

Buildings are no different in their operation to brains and cars in that they are complex systems and possess emergent properties. Buildings might be 'machines that people live in' (Le Corbusier 1923) but, in terms of 'technologies', which are by definition properties or processes that are quantitatively tangible and measurable, buildings are (amongst other things) thermal machines. Emergent thermal properties cannot be precisely ascertained from a knowledge of only single built features. They are the temporally and spatially holistic result of the interaction between the physical components in a built system and their thermal properties operating in conjunction with the natural elements (sun, water, wind etc.) (Fig. 1), although some thermal features will generally have a greater influence over the outcome than others. For example, the characteristics of the material of a building's wall or roof will have a greater influence on the overall thermal performance than the colour of its furnishings.

Thermal environments are highly sensitive to small changes, such as changes to the buildings themselves, changes to the fixtures and fittings, the occupants and the outside environment. The number of individual thermal states that can potentially be achieved within a space is infinite and it is not possible to know precisely what thermal states will result from effecting a change to a built system. This is because small changes can have large-scale, long-term effects (Szokolay 1987: 21; Clarke 2001ix). In other words, emergent thermal properties must be studied at the scale of the whole thermal system, at the scale of interrelated assemblages of built parts and thermal features. 
The main factors upon which emergent thermal properties are predicated are:

1. the characteristics and properties of the building envelope,

2. the way the building sits in the landscape (the characteristics and properties of its surroundings and climate),

3. the arrangement, characteristics and properties of individual rooms, and

4. the presence or absence of active heating and/or cooling systems (fires etc.).

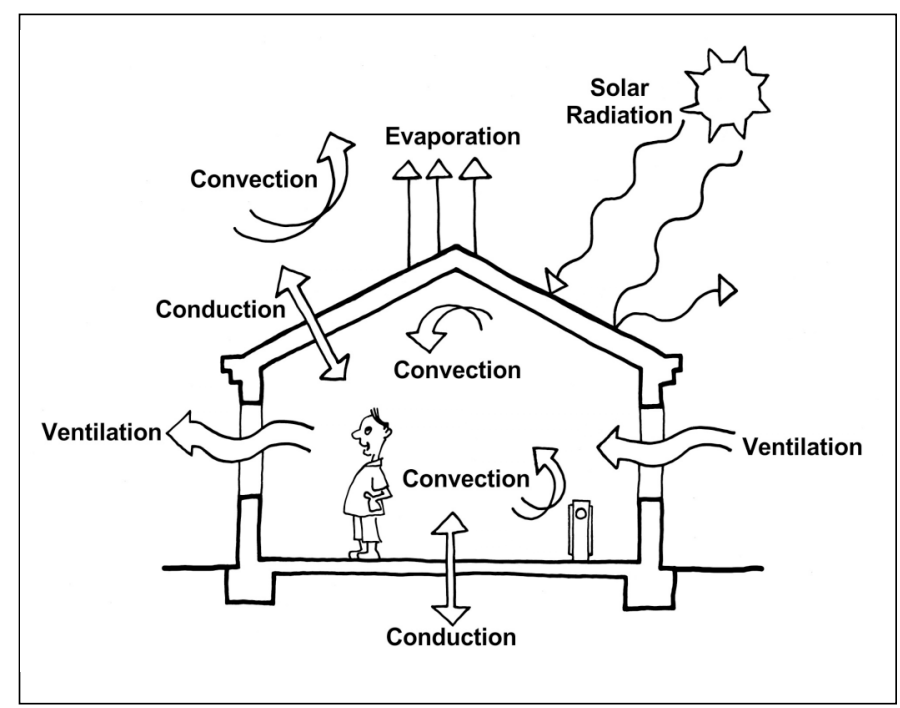

Figure 1: Thermal Exchange Between Buildings and their Environment

\section{Emergent Properties as Functional Capacity}

Emergent properties can be equated to the functional capacity of a system, to the potential of a system to achieve a range of individual states. A car possesses the capacity to achieve a range of states, from stationary to full-speed, and it retains this capacity whether the engine is running or not (as long as no other fundamental changes are made), because it possesses the property 'capacity to move'. The nature of the emergent properties will vary, however, from class to class (from make or model to make or model). Mazeratis, for example, constitute a separate class of car to Mini Minors or Bentleys. A building's emergent thermal properties can also be equated to the its thermal capacity. A building's thermal capacity is defined by the range of thermal states and microclimates the building can achieve and the degree to which these can be selectively altered. A building's thermal capacity can, therefore, be used to define its thermal class. Windbreaks, for example, constitute a different thermal class to enclosed huts.

It is, however, possible to redefine a building's thermal capacity in humanistic terms. The range of thermal states and microclimates that a building is capable of capable of providing to its occupants can be redefined in terms of the occupants' thermal choices and the degree to which these can be selectively altered can be redefined in terms of the occupants' degree of thermal control.

Thermal choices and thermal control are often contradictory. This is because thermal choices are a factor of microclimatic variability: the range of different microclimates available to a person that they can choose to move between and/or occupy. Thermal control, conversely, is a factor of ambient homogeneity: it is easier to selectively control and/or alter something that is already homogenous than if it is variable. For example, a room that is environmentally homogenous and static would offer little thermal choice, but it would be relatively easy to raise the ambient temperature by an even $1^{\circ} \mathrm{C}$. Conversely, a room in which there is a wide and diverse range of microclimates would offer a lot of thermal choices, but raising the temperature of each microclimatic zone by an even $1^{\circ} \mathrm{C}$ would be very difficult. Providing maximum thermal choices and maximum thermal control within a single structure is, therefore, inherently difficult, because as one is enhanced by accentuating certain thermal traits the other is often degraded, and vice versa. For example, the thermal properties of a brick wall, which conducts heat very slowly, is potentially contradicted by the presence of a large single-glazed window inset into it, which conducts heat rapidly. 


\section{$5 \quad$ The Long Term Trend}

The emergent properties of 158 pre-industrial vernacular buildings (assemblages of interconnected rooms) were examined over a period of time that dated back to the earliest built structures within each of the three study regions: Pakistan (late $4^{\text {th }}$ Mill. B.C. - early $20^{\text {th }}$ C. A.D.), Egypt (early $4^{\text {th }}$ Mill. B.C. - early $20^{\text {th }}$ C. A.D.) and Palestine ( $7^{\text {th }}$ Mill. B.C. - early $10^{\text {th }}$ C. A.D.). The buildings (entities), from twenty-seven different sites, were allocated into seventeen groups according to region and period. The buildings were treated as composites of forty interrelated built and thermal properties (variables), which represent the main factors upon which emergent thermal properties are predicated (Table 1). The variables were given numerical values equivalent to their capacity to provide thermal choices or thermal control, or both (Table 1 and Fig. 2). The numerical values were derived from the results of an engineering-analysis (ref. Wilkins 2007; Wilkins 2006), an analytical methodology developed within the sciences to investigate the contradictory processes operating within complex systems and thus ideal for investigating the contradictory nature of thermal choices and thermal control (Carlson \& Doyle 1999; Jen 2005a \& b).

\begin{tabular}{|c|c|c|c|}
\hline $\begin{array}{c}\text { Feature } \\
\text { (Variable) } \\
\text { No. }\end{array}$ & Built and/or Thermal Features (Variables) & $\begin{array}{l}\text { Reference } \\
\text { Illustration } \\
\text { in Figure } 2\end{array}$ & \\
\hline $1-9$ & $\begin{array}{l}\text { Building exposure (n, ne, nw, s, se, sw, e, w } \\
\qquad \text { \& vertical) }\end{array}$ & A & \multirow{13}{*}{$\begin{array}{l}\text { Features where } \\
\text { thermal choices } \\
\text { and thermal control } \\
\text { are contradictory }\end{array}$} \\
\hline $10-11$ & Roof flatness/peakiness and range & B & \\
\hline $12-13$ & $\begin{array}{c}\text { Floor level relative to ground level and } \\
\text { range }\end{array}$ & C & \\
\hline $14-16$ & $\begin{array}{c}\text { Wall and roof material (thermal mass) and } \\
\text { roof material range }\end{array}$ & $\mathrm{D}$ & \\
\hline $17-18$ & Presence of wall \& roof insulation & $\mathrm{E}$ & \\
\hline $19-20$ & No. internal angles and range & $\mathrm{F}$ & \\
\hline $21-22$ & Ratio length/width and range & G & \\
\hline $23-24$ & No. posts and range & $\mathrm{H}$ & \\
\hline 25 & No. niches & 1 & \\
\hline 26 & No. fixed benches & J & \\
\hline 27 & Compactness/longevity & K & \\
\hline 28 & No. rooms & L & \\
\hline $29-30$ & Internal floor/ceiling thermal conductivity & M & \\
\hline 31 & No. roofs at different levels & $\mathrm{N}$ & \multirow{6}{*}{$\begin{array}{c}\text { Features where } \\
\text { thermal choices } \\
\text { and thermal control } \\
\text { are not } \\
\text { contradictory }\end{array}$} \\
\hline 32 & Degree of opening in each direction & $\mathrm{O}$ & \\
\hline $33-37$ & Solar penetration (from s, se, sw, e, w) & $\mathrm{P}$ & \\
\hline 38 & Cross ventilation & Q & \\
\hline 39 & Heating & $\mathrm{R}$ & \\
\hline 40 & Degree of transitional space & S & \\
\hline
\end{tabular}

Table 1: The Built and Thermal Features

This data was then analysed via a type of statistical multivariate analysis (MVA) known as discriminant analysis. There are three reasons why MVA is ideally suited to analysing emergent thermal properties. First, it can quantitatively analyse large numbers of entities (buildings) that are composed of large arrays of interacting variables (built features and thermal properties). Secondly, it can illuminate trends and patterns within large arrays of complex interrelated data that are impossible to discern by simple means. Multivariate data, data composed of numerous variables, 
requires a graph of numerous dimensions upon which to plot them. This becomes visually and cognitively impossible to comprehend. MVA, however, reduces the variables to a smaller number, two or three, which still retain the underlying structure of the original data. These are known as Functions and the first two functions capture the most information about the original data. The smaller number of variables can then be easily interpreted, either numerically in table form, or graphically on a two-dimensional plot or scattergram that contains the first two functions (Shennan 1988: 241). Thirdly, MVA can specifically model the thermal behaviour of buildings because it equates the entities (the buildings) with their composite strings of conjoined and interrelated variables (built features and traits), including feedback between the operations (Plog, 1974: 150). A discriminant therefore shows the sum of the variables of each building relative to the sum of the variables of each other building: the emergent thermal properties of each building relative to each other building.

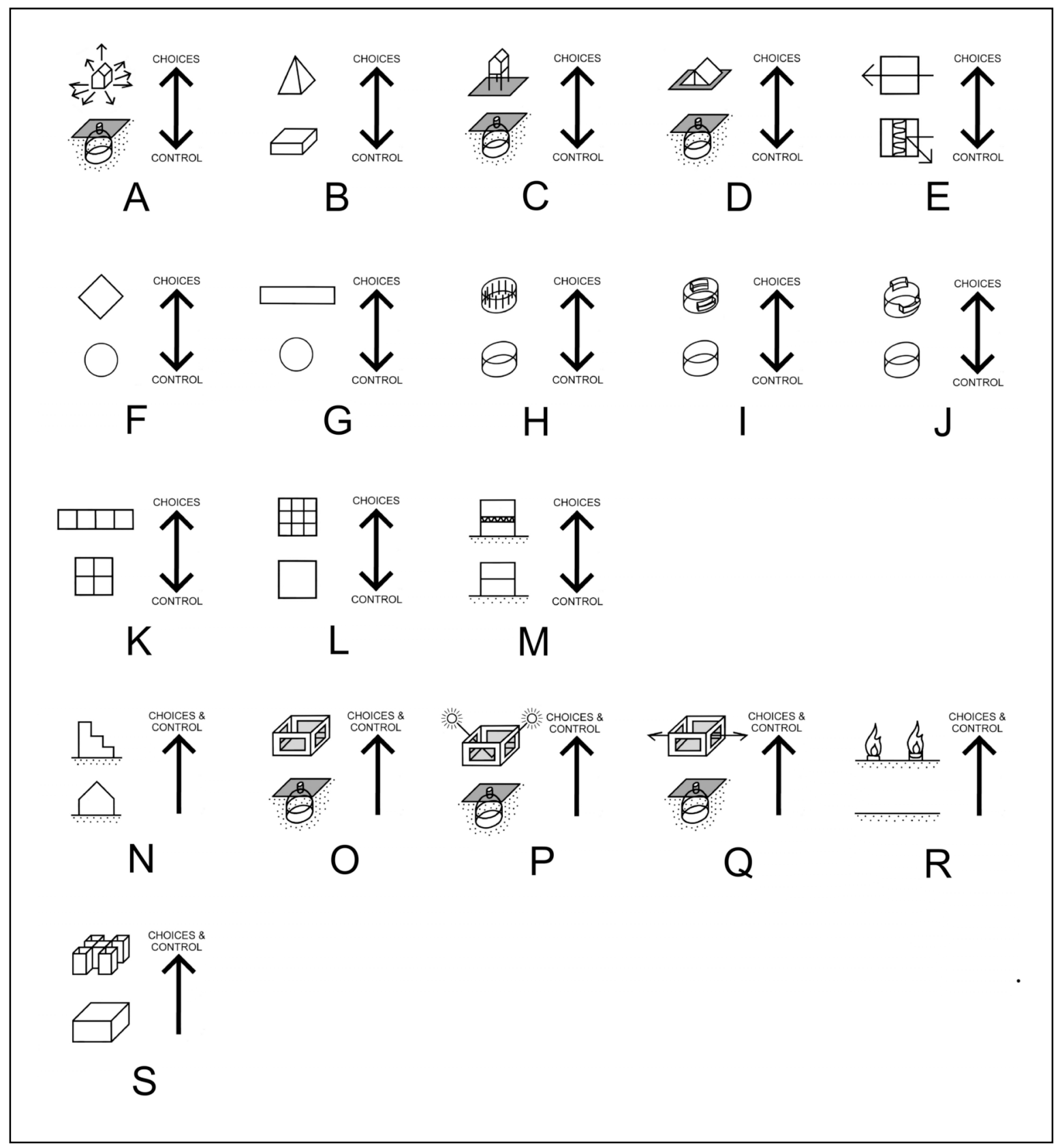

Figure 2: The Built and Thermal Features according to Thermal Choices and Control

The resultant discriminant scatterplot (Fig. 3) shows that the emergent thermal properties (thermal capacities) altered discernibly and gradually over time, a trend that was statistically meaningful ( $r=$ $0.818 ; p=0.000)$. The trend is characterised by minimal inter-building thermal variability, as indicated by the relative sizes of the scattergram clusters, up until the pre-industrial era when inter- 
building thermal variability increased. More importantly, however, the trend is characterised by a general overall increase in building complexity and thermal sophistication. This has allowed the overall level of thermal choices and control available to building occupants to increase over time, regardless of their contradictory natures. The later vernacular buildings of Egypt and Pakistan (there are no vernacular examples for the Palestinian highlands) were highly complex, with more rooms, more levels, more transitional spaces, more courtyards, and more variation in room size and shape, than their predecessors. That is, they possessed a wide range of potentially different thermal environments: high thermal choices. They were also highly thermally sophisticated, with more environmentally-altering devices, such as windcatchers, evaporative coolers, fire braziers and closeable-openings with diverse types of shutters and screens, than their predecessors. That is, they possessed the capacity to be selectively thermally altered: high thermal control (Wilkins 2005). These buildings represent a class of building that is long lasting and which has only recently begun to be replaced in an age when mechanical heating and cooling are readily available.

The scatterplot, however, shows two exceptions to the overall trend towards increasing thermal choices and control. The first is the very early Naqada 1 buildings in Egypt which appear as an outlier group. The second is the Harappan buildings of Pakistan. These buildings, c. 2600-1900 B.C., were characteristically of massive, load-bearing brick construction, were highly thermally homogenous and static and were inherently difficult to alter, both physically and thermally (Wilkins 2005). These buildings, however, represent a class of building that fell out of use and which has not reappeared.

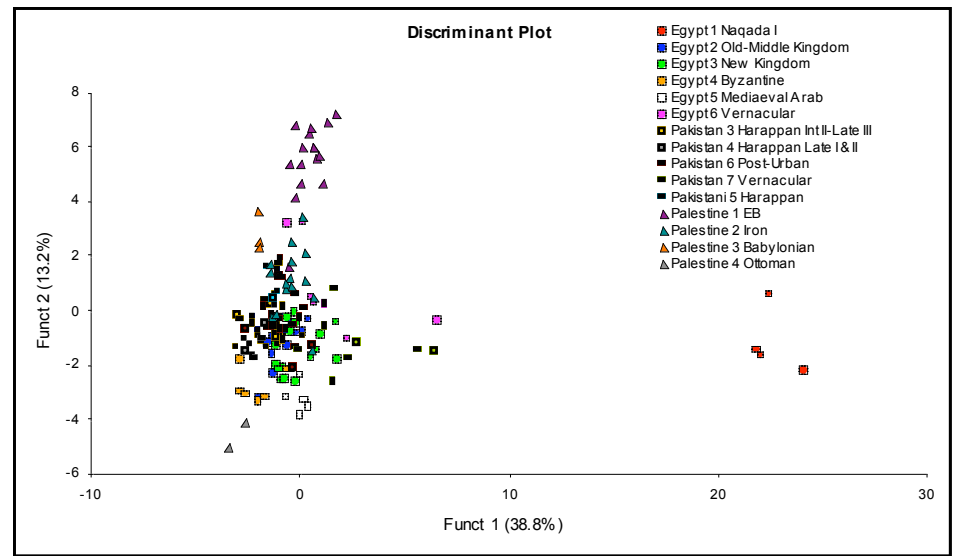

Figure 3: Discriminant Plot of Emergent Thermal Properties (Thermal Capacities)

\section{Conclusions: Thermal Innovations Over Time}

Buildings possess emergent thermal properties. These are empirically measurable, high-level behaviours that arise spontaneously as a result of the structural organisation of, and the interactions between, the physical parts and thermal properties of buildings and the built environment. The earliest buildings possessed emergent thermal properties that differed only in degree, not in kind, from later, vastly more complex buildings. However, later buildings developed ever more sophisticated technologies for 'managing' the emergent thermal properties, and their inherent contradictions, whether the people involved were aware of this or not. "Perhaps they did not know technically what they were doing or why, but the results were effective, comfortable and practical" (Stead 1980: 41). More importantly, this development occurred in a way that enhanced the built environment's capacity to provide thermal choices and control, even though their contradictory natures makes finding technologies that concurrently enhance both exponentially more difficult (Kauffman 1995: 203-205). That is, over time silent technologies developed within the built environment such that ever more people possessed the potential be more thermally satisfied for more of the time.

\section{References}

Ballinger, J.A. Solarch Handbook for the Thermal Design of Buildings. Sydney: University of New South Wales, 1983.

Carlson, J. \& Doyle, J. "Highly Optimized Tolerance: Robustness and Power Laws in Complex Systems". Physical Review E 60 (1999): 1412-1427.

Clarke, J.A. Energy Simulation in Building Design. Oxford: Butterworth-Heinemann, 2001. 
Cohen, J. \& Stewart, I. The Collapse of Chaos: Discovering Simplicity in a Complex World. London: Penguin Books Ltd, $3^{\text {rd }}$ Ed., 2000.

Conway Morris, S. The Crucible of Creation: The Burgess Shale and the Rise of Animals. Oxford: University Press, 1998.

Eldredge, N. Macroevolutionary Dynamics: Species, Niches and Adaptive Peaks. New York: McGraw-Hill Publishing Co., 1989.

Gould, S.J. \& Lewontin, R. "The Spandrels of San Marco and the Panglossian Paradigm: A Critique of the Adaptationist Programme", in Sober, E. (ed.) Conceptual Issues in Evolutionary Biology: An Anthology, Cambridge, Massachusetts: MIT Press, 1984: 253-270.

Jeanneret, C.-E. "Le Corbusier". Vers une Architecture. 1923.

Jen, E. (a) "Introduction", in Jen, E. (ed.) Robust Design: A Repertoire of Biological, Ecological and Engineering Case Studies. Oxford: University Press, 2005: 1-6.

Jen, E. (b) "Stable or Robust? What's the Difference?", in Jen, E. (ed.) Robust Design: A Repertoire of Biological, Ecological and Engineering Case Studies. Oxford: University Press, 2005: 7-20.

Kauffman, S.A. At Home in the Universe: The Search for the Laws of Complexity. London: Penguin Group, 1995.

Maxwell, T.D. "Directionality, Function and Adaptation in the Archaeological Record", in Hurt, T.D. \& Rakita, G.F.M. (eds.) Style and Function: Conceptual Issues in Evolutionary Archaeology. Westport, Connecticut: Bergin \& Garvey, 2001: 41-50.

Plog, F.T. The Study of Prehistoric Change. New York: Academic Press, 1974.

Shennan, S. Quantifying Archaeology. Edinburgh: University Press, 1988.

Stead, P. "Lessons in Tradition and Vernacular Architecture in Arid Zones", in Golany, G. (ed.) Housing in Arid Lands: Design and Planning. London: The Architectural Press, 1980: 33-44.

Szokolay, S.V. Thermal Design of Buildings. Canberra: RAIA Education Division, 1987.

Wilkins, H. "From Massive to Flimsy: The Declining Structural Fabric at Mohenjo-daro", in FrankeVogt, U. \& Weisshar, H.-J. (eds.), South Asian Archaeology 2003, Proceedings of the Seventeenth International Conference of South Asian Archaeologists (7-11 July 2003, Bonn). Aachen: Linden Soft, 2005: 137-146.

Wilkins, H. The Evolution of the Built Environment: Complexity, Human Agency and Thermal Performance. Unpublished Ph.D Thesis. University of Sydney: Department of Archaeology, 2006.

Wilkins, H. "An Investigation of the Adaptive Opportunity of Rudimentary Structures Based on Field Experiments". Building and Environment 42(11) (2007): 3883-3893.

\section{Acknowledgements}

This work was funded by the Australian Government APA program and the Sydney University PRSS. 